\title{
Synthesis, Structural Characterization, and Catalytic Property of A Zn(II) Complex with 5-Bromosalicylaldehyde Ligand
}

\author{
Xi-Shi Tai ${ }^{1}$, Peng-Fei Li ${ }^{2}$, Xin Wang ${ }^{3}$, Li-Li Liu ${ }^{1, *}$ \\ ${ }^{1}$ College of Chemistry and Chemical Engineering, Weifang University, Weifang 261061, P.R. China \\ ${ }^{2}$ College of Chemical Engineering, Qingdao University of Science and Technology, \\ Qingdao 266061, P.R. China \\ ${ }^{3}$ Department of Chemistry, Qinghai Normal University, Xining 810008, P.R. China
}

Received: $25^{\text {th }}$ December 2016; Revised: $10^{\text {th }}$ March 2017; Accepted: $10^{\text {th }}$ March 2017; Available online: 27th October 2017; Published regularly: December 2017

\begin{abstract}
The study on catalytic activity of complex materials has been one of the hot spots in coordination chemistry. In order to extensively study the catalytic activity of complexes, a new six-coordination $\mathrm{Zn}$ (II) complex material, $\left[\mathrm{ZnL}_{2}\left(\mathrm{H}_{2} \mathrm{O}\right)_{2}\right](\mathbf{C 1})(\mathrm{HL}=5$-bromosalicylaldehyde), has been prepared with 5bromosalicylaldehyde, $\mathrm{NaOH}$, and $\mathrm{Zn}\left(\mathrm{CH}_{3} \mathrm{COO}\right)_{2} \cdot 2 \mathrm{H}_{2} \mathrm{O}$ as raw materials. The structure of $\mathbf{C 1}$ was determined by elemental analysis, IR spectra, and single crystal X-ray diffraction. The Zn(II) complex shows a moderate catalytic activity for $\mathrm{A}^{3}$ coupling reaction of benzaldehyde, piperidine, and phenylacetylene with the benzaldehyde conversion reached $54.6 \%$. Furthermore, the Zn(II) complex catalyst exhibited $54.8 \%, 53.8 \%$, and $54.4 \%$ conversions of benzaldehyde in the second, third, and fourth cycles, respectively. In addition, the $\mathrm{Zn}$ (II) complex features a selectivity of $100 \%$ to the product of propargylamine for the $\mathrm{A}^{3}$ coupling reaction. Copyright (C) 2017 BCREC Group. All rights reserved
\end{abstract}

Keywords: Zn(II) complex material; Synthesis; Structural characterization; Catalytic property; Ligand

How to Cite: Tai, X.S., Li, P.F., Wang, X., Liu, L.L. (2017). Synthesis, Structural Characterization, and Catalytic Property of A Zn(II) Complex with 5-Bromosalicylaldehyde Ligand. Bulletin of Chemical Reaction Engineering \& Catalysis, 12(3): 364-369 (doi:10.9767/bcrec.12.3.876.364-369)

Permalink/DOI: https://doi.org/10.9767/bcrec.12.3.876.364-369

\section{Introduction}

Propargylamines are versatile synthetic intermediates in organic synthesis and are also important structural elements in natural products and therapeutic drug molecules, and are used for the synthesis of polyfunctional amino derivatives [1-3]. They were synthesized by three component coupling reaction $\left(\mathrm{A}^{3}\right.$ coupling) of aldehydes, alkynes and amines [4-6]. How-

* Corresponding Author.

E-mail: taixs@wfu.edu.cn (Tai, X.S.)

Telp.: +86-536-8785363 ; Fax.: +86-536-8785363 ever, the traditionally catalysts used in the synthesis of propargylamines require very harsh reaction conditions, for example, they must be used in stoichiometric amounts, are highly moisture sensitive, and require strictly controlled reaction conditions [7].

In recent years, many chemists have been working on synthetic catalysts which could be used in mild condition. Therefore, different transition metals have been used as the catalysts for these reactions, such as: gold [4], silver [5], zinc [8], copper [9], and nickel [10]. Metal complex materials have also attracted attention 
due to their catalytic activity for many reactions [11-16]. Studies on the synthesis and catalytic activity of metal complexes have been the goal of our research group [17,18]. Herein, in this paper, a new six-coordination $\mathrm{Zn}$ (II) complex material was synthesized and characterized by elemental analysis, IR spectra and single crystal X-ray diffraction. The catalytic activity for $\mathrm{A}^{3}$ coupling reaction has also been investigated with $\mathrm{Zn}$ (II) complex as the catalysts.

\section{Experimental}

\subsection{Materials and measurements}

The analytical grade reagents used in this e x p e r imental works were: 5-bromosalicylaldehyde, $\quad \mathrm{Zn}\left(\mathrm{CH}_{3} \mathrm{COO}\right)_{2} \cdot 2 \mathrm{H}_{2} \mathrm{O}$, $\mathrm{NaOH}$, benzaldehyde, piperidine, phenylacetylene, and 1, 4-dioxane. Elemental analyses (C, $\mathrm{H}$, and $\mathrm{N}$ ) were measured on an Elementar Vario III EL Elemental Analyzer. IR spectra were measured on a Nicolet AVATAR 360 infrared spectrometer in the $4000-400 \mathrm{~cm}^{-1}$ region. The structural data of $\left[\mathrm{ZnL}_{2}\left(\mathrm{H}_{2} \mathrm{O}\right)_{2}\right]$ were collected by a Bruker Amart CCD diffractometer.

\subsection{Synthesis of $\left[\mathrm{ZnL}_{2}\left(\mathrm{H}_{2} \mathrm{O}\right)_{2}\right](\mathrm{C} 1)$}

Ten mL ethanol solution of 5-bromosalicylaldehyde (1.0 mmol, $0.2010 \mathrm{~g})$ and $\mathrm{NaOH}(1.0 \mathrm{mmol}, 0.040 \mathrm{~g})$ was added to the solution of $5 \mathrm{~mL}$ ethanol/water $(\mathrm{v}: \mathrm{v}=1: 1)$ containing $\mathrm{Zn}\left(\mathrm{CH}_{3} \mathrm{COO}\right)_{2} \cdot 2 \mathrm{H}_{2} \mathrm{O} \quad(0.5 \mathrm{mmol}$, $0.1097 \mathrm{~g})$. The mixture turned light yellow transparent solution. Then, the mixture was heated to $60{ }^{\circ} \mathrm{C}$ and maintained at this temperature for $5 \mathrm{~h}$ while stirring. Light yellow crystals of $\left[\mathrm{ZnL}_{2}\left(\mathrm{H}_{2} \mathrm{O}\right)_{2}\right]$ was achieved by slowly evaporating the filtrate at room temperature (yield $c a .82 \%$ based on $\mathrm{Zn}\left(\mathrm{CH}_{3} \mathrm{COO}\right)_{2} \cdot 2 \mathrm{H}_{2} \mathrm{O}$ ).

\subsection{X-ray crystallography}

The single crystal data of $\left[\mathrm{ZnL}_{2}\left(\mathrm{H}_{2} \mathrm{O}\right)_{2}\right](\mathbf{C 1})$ with dimensions of $0.22 \mathrm{~mm} \times 0.19 \mathrm{~mm} \times 0.18$ $\mathrm{mm}$ was collected on a Bruker Smart CCD diffractometer at $293 \mathrm{~K}$ with graphitemonochromatic Mo $K a$ radiation $(\lambda=0.71073$ $\AA)$. In the range of $3.03<\theta<25.01$, a total of 12283 reflections were collected and 5532 were independent with $R_{\text {int }}=0.1099$, of which 2136 were observed with $I>2 \sigma(I)$. The structure was solved by direct methods with SHELXS-97 [19] and refined by full-matrix least-squares techniques on $F^{2}$ with SHELXL-97 [20].

\subsection{General procedure for the three- component coupling reaction $\left(\mathrm{A}^{3}\right)$}

Typical procedure for the three-component $\left(\mathrm{A}^{3}\right)$ coupling reaction: a mixture of benzaldehyde $(0.125 \mathrm{mmol}, 0.014 \mathrm{~g})$, phenylacetylene $(0.165 \mathrm{mmol}, 0.017 \mathrm{~g})$, piperidine $(0.150 \mathrm{mmol}$, $0.013 \mathrm{~g}$ ), and $\mathrm{Zn}(\mathrm{II})$ complex catalyst (0.070 g) were added into 1,4-dioxane (1.500 g). The reaction mixtures were put into a closed glass reactor $(8 \mathrm{~mL})$ and were extensively stirred at $120{ }^{\circ} \mathrm{C}$ for $12 \mathrm{~h}$. At the end of each catalytic $\mathrm{A}^{3}$ coupling reaction, the catalysts were isolated by centrifugation from the reaction solution, dried at $50{ }^{\circ} \mathrm{C}$ under vacuum for $5 \mathrm{~h}$, and then reused in the next run of each reaction. The products were analyzed using a gas chromatograph (GC-1100) equipped with a SE-54 capillary column and a hydrogen flame detector.

\section{Results and Discussion}

\subsection{EA and IR spectra of $\left[\mathrm{ZnL}_{2}\left(\mathrm{H}_{2} \mathrm{O}\right)_{2}\right](\mathrm{C} 1)$}

The IR spectra of $\left[\mathrm{ZnL}_{2}\left(\mathrm{H}_{2} \mathrm{O}\right)_{2}\right](\mathbf{C} \mathbf{1})$ is given in Figure 1. The IR spectrum of 5-bromosalicylaldehyde showing strong absorption band at $1672 \mathrm{~cm}^{-1}$ may be assigned to the characteristic band of $-\mathrm{C}(\mathrm{O})-$ of 5-bromosalicylaldehyde. In $\left[\mathrm{ZnL}_{2}\left(\mathrm{H}_{2} \mathrm{O}\right)_{2}\right](\mathbf{C 1})$, the characteristic band of $-\mathrm{C}(\mathrm{O})$ - appears at $1631 \mathrm{~cm}^{-1}$, which indicating that the $\mathrm{O}$ atom of $-\mathrm{C}(\mathrm{O})$ - coordinates to the $\mathrm{Zn}(\mathrm{II})$ ion. Besides, the band at $3443 \mathrm{~cm}^{-1}$ shows that the $\mathrm{Zn}$ (II) complex containing water molecules [21]. The IR results show that $\left[\mathrm{ZnL}_{2}\left(\mathrm{H}_{2} \mathrm{O}\right)_{2}\right]$ (C1) is formed, which is consistent with element and $\mathrm{X}$-ray single crystal analysis. Elemental analysis calculated for $\mathrm{C}_{14} \mathrm{H}_{12} \mathrm{Br}_{2} \mathrm{O}_{6} \mathrm{Zn}$ (\%) is C, 33.50; and H, 2.39. Meanwhile, found elemental analysis (\%) is: C, 33.26; and H, 2.49.

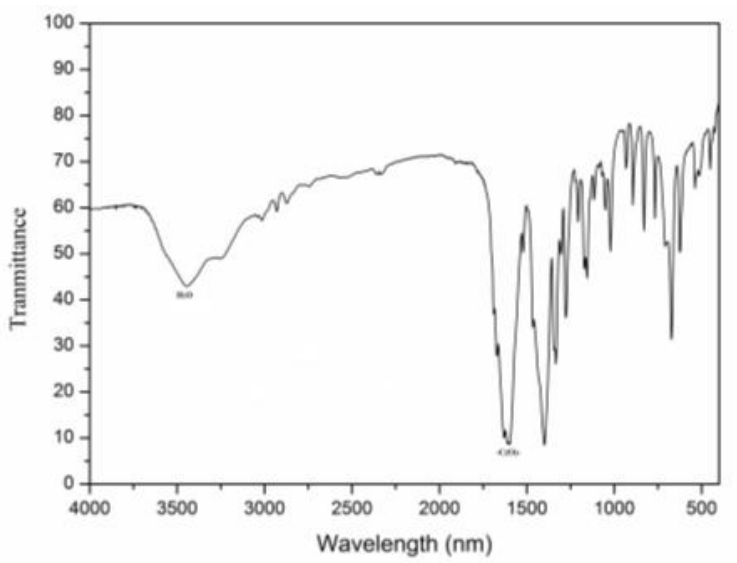

Figure 1. IR spectra of 5-bromosalicylaldehyde and $\left[\mathrm{ZnL}_{2}\left(\mathrm{H}_{2} \mathrm{O}\right)_{2}\right](\mathbf{C 1})$ 
The selected IR bands $(\mathrm{KBr})$ were: $3443 \mathrm{~cm}^{-1}$ $\left(\mathrm{H}_{2} \mathrm{O}\right), 1631 \mathrm{~cm}-1$ (-C(O)-).

\subsection{Structural description of $\left[\mathrm{ZnL}_{2}\left(\mathrm{H}_{2} \mathrm{O}\right)_{2}\right]$ (C1)}

Structural analysis suggests that the $\mathrm{Zn}(\mathrm{II})$ complex (C1) crystallizes in triclinic $P$-1 space group. The coordination environment of $\mathrm{Zn}$ (II) center in $\mathbf{C 1}$ is shown in Figure 2. The selected bond distances and angles of complex $\mathbf{C} 1$ are listed in Table 2. The $\mathrm{Zn}(\mathrm{II})$ complex (C1) consists of a $\mathrm{Zn}(\mathrm{II})$ ions, two 5bromosalicylaldehyde ligands with losing of proton, and two coordinated water molecules. The $\mathrm{Zn}$ (II) ion in $\mathbf{C 1}$ is surrounded by four $\mathrm{O}$ atoms from two 5-bromosalicylaldehyde ligands and $\mathrm{O}$ atoms from two coordinated water molecules, which resulting in a distorted octahedral coordination environment (Figure 3). The four coordinated $\mathrm{O}$ atoms of $\mathrm{O} 1, \mathrm{O} 2, \mathrm{O} 3$ and $\mathrm{O} 4$ from 5-bromosalicylaldehyde ligands are in the equatorial plane and the two coordinated $\mathrm{O}$ atoms of $\mathrm{O} 1 \mathrm{~W}$ and $\mathrm{O} 2 \mathrm{~W}$ from coordinated water molecules are situated axial place. The $\mathrm{Zn}-\mathrm{O}$ bond distances range from 2.011(8) $\AA$ to 2.190(7) $\AA$, which are closed to those of

Table 1. Crystal data and refinement details for $\mathbf{C 1}$

\begin{tabular}{|c|c|}
\hline Empirical formula & $\mathrm{C}_{14} \mathrm{H}_{12} \mathrm{ZnBr}_{2} \mathrm{O}_{6}$ \\
\hline Formula weight & 501.43 \\
\hline Temperature/K & $293(2)$ \\
\hline Crystal system & triclinic \\
\hline Space group & $P-1$ \\
\hline$a / \AA ̊$ & $9.5560(19)$ \\
\hline$b / \AA$ & $12.588(3)$ \\
\hline$c / \AA$ & $14.945(3)$ \\
\hline$a /^{\circ}$ & $98.53(3)$ \\
\hline$\beta /^{\circ}$ & $99.11(3)$ \\
\hline$\gamma /{ }^{\circ}$ & $112.29(3)$ \\
\hline Volume $/ \AA^{3}$ & $1599.1(6)$ \\
\hline$Z$ & 4 \\
\hline$\rho_{\text {calc }} \mathrm{mg} / \mathrm{mm}^{3}$ & 2.083 \\
\hline$\mu / \mathrm{mm}^{-1}$ & 6.559 \\
\hline$S$ & 1.049 \\
\hline$F(000)$ & 976 \\
\hline Index ranges & $\begin{array}{l}-11 \leq h \leq 11, \\
-14 \leq k \leq 14, \\
-17 \leq l \leq 17\end{array}$ \\
\hline Reflections collected & 12283 \\
\hline Independent reflections & $5532[R(\mathrm{int})=0.1099]$ \\
\hline Data/restraints/parameters & $5532 / 0 / 418$ \\
\hline Goodness-of-fit on $F^{2}$ & 1.049 \\
\hline Final $R$ indexes $[I \geq 2 \sigma(I)]$ & $R_{1}=0.2382, w R_{2}=0.1992$ \\
\hline Final $R$ indexes [all data] & $R_{1}=0.1236, w R_{2}=0.0818$ \\
\hline
\end{tabular}

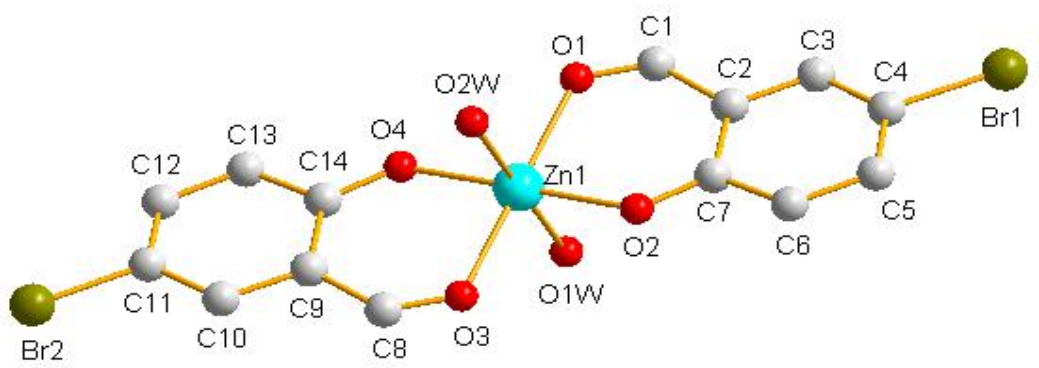

Figure 2. Coordination environment of $\mathrm{Zn}$ (II) center in $\mathbf{C 1}$ 
$\mathrm{Zn}$ (II) complexes [22]. The distances of $\mathrm{C} 1-\mathrm{O} 1$ and $\mathrm{C} 14-\mathrm{O} 4$ are longer than those of $\mathrm{C} 7-\mathrm{O} 2$ and C8-O3, which suggest that $\mathrm{C} 1-\mathrm{O} 1$ and $\mathrm{C} 14-\mathrm{O} 4$ are double bonds. In the complex C1, two sixmember rings were formed by the coordinated effect of $\mathrm{Zn}(\mathrm{II})$ ion with $\mathrm{O} 1, \mathrm{O} 2, \mathrm{O} 3$ and $\mathrm{O} 4$ atoms, and the dihedral angle between the ring 1 (C8-C9-C14-O4-Zn1-O3) and ring 2 (C1-C2-C7$\mathrm{O} 2-\mathrm{Zn} 1-\mathrm{O} 1)$ is 0.6 (3) ${ }^{\circ}$. The $1 \mathrm{D}$ chained structure was formed through the effect of $\mathrm{O}-\mathrm{H} \cdots \mathrm{O}$ hydrogen bonds between the adjacent $\mathbf{C 1}$ molecules (Figure 4). The perspective view of stacking is shown in Figure 5. Main crystal data and refinement details of $\mathbf{C 1}$ are listed in Table 1.

\subsection{Catalytic studies}

The catalytic activity of $\mathrm{Zn}(\mathrm{II})$ complex catalyst was tested for $\mathrm{A}^{3}$ coupling reaction of bezaldehyde, piperidine, and phenylacetylene with 1,4-dioxane as a solvent. The results are summarized in Table 3. The $\mathrm{Zn}$ (II) complex catalyst shows a moderate catalytic activity, and the benzaldehyde conversion reached 54.6 $\%$ for $12 \mathrm{~h}$ at $120{ }^{\circ} \mathrm{C}$. Furthermore, the $\mathrm{Zn}(\mathrm{II})$ complex catalyst exhibited $54.8 \%, 53.8 \%$, and $54.4 \%$ conversions of benzaldehyde at $120{ }^{\circ} \mathrm{C}$ for $12 \mathrm{~h}$ in the second, third, and fourth cycles, respectively. The $\mathrm{Zn}$ (II) complex catalyst could be recovered easily by centrifugation and re-

Table 2. The selected important bond parameters of complex $\mathbf{C 1}$

\begin{tabular}{cccc}
\hline Bond & Distance $(\AA)$ & Angle & $\left({ }^{\circ}\right)$ \\
\hline Zn1-O1 & $2.118(8)$ & O4-Zn1-O2 & $179.4(4)$ \\
zn1-O4 & $2.011(8)$ & O4-Zn1-O3 & $87.4(3)$ \\
Zn1-O2 & $2.023(8)$ & O2-Zn1-O3 & $92.1(3)$ \\
Zn1-O3 & $2.104(8)$ & O4-zn1-O1 & $92.8(3)$ \\
Zn1-O1W & $2.179(6)$ & O1-Zn1-O2 & $87.7(3)$ \\
Zn1-O2W & $2.190(7)$ & O1-Zn1-O3 & $179.7(4)$ \\
& & O4-Zn1-O1W & $89.7(3)$ \\
& & O2-Zn1-O1W & $90.6(3)$ \\
& & O3-Zn1-O1W & $93.2(3)$ \\
& & O1-Zn1-O1W & $87.0(3)$ \\
& & O4-Zn1-O2W & $90.8(3)$ \\
& & O2-Zn1-O2W & $88.9(3)$ \\
& & O3-Zn1-O2W & $87.2(3)$ \\
& & O1-Zn1-O2W & $92.6(3)$ \\
& & O2-Zn1-O2W & $179.4(4)$ \\
\hline
\end{tabular}

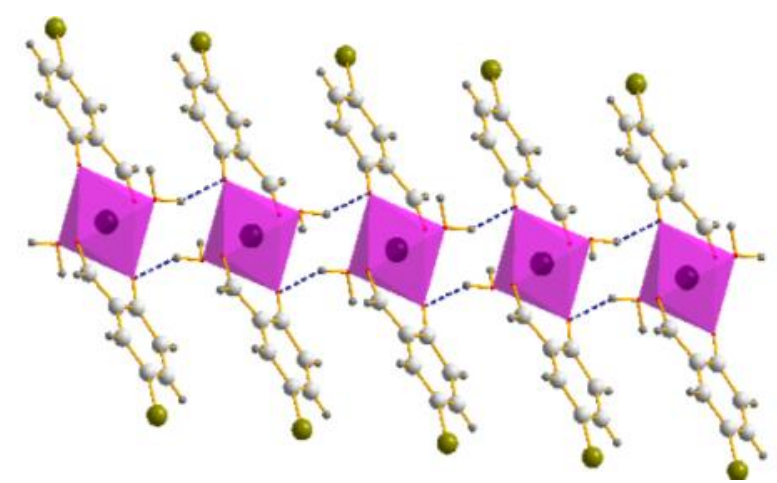

Figure 3. Coordination polyhedra of $\mathrm{Zn}$ (II) complex C1

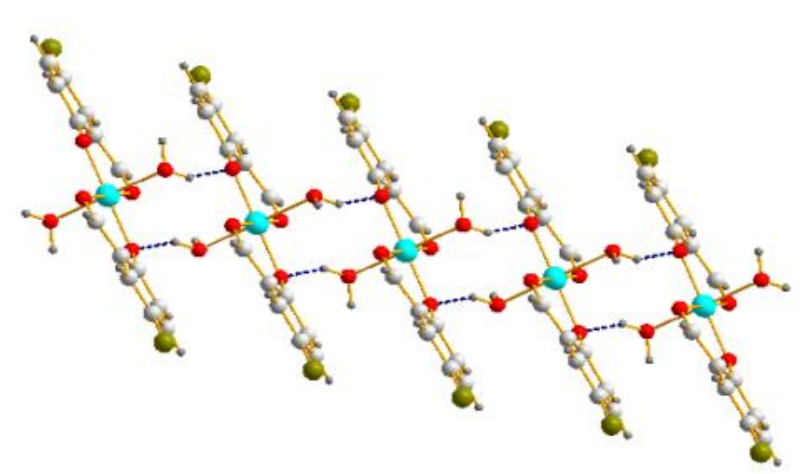

Figure 4. The H-Bonds interaction in $\mathrm{Zn}(\mathrm{II})$ complex $\mathbf{C 1}$ 
used up to four times without any decrease in catalytic activity. It means that an active site is a part of the $\mathrm{Zn}$ (II) complex catalyst and is not reduced. Moreover, the $\mathrm{Zn}$ (II) complex catalyst features a selectivity of $100 \%$ to the product of propargylamine for the $\mathrm{A}^{3}$ coupling reaction. These features render the catalysts of $\mathrm{Zn}$ (II) complex particularly attractive in the practice of propargylamines synthesis in an environmentally friendly manner.

\section{Conclusions}

In summary, a new $\mathrm{Zn}$ (II) complex material has been prepared, and its structure was determined by elemental analysis, IR spectra, and single crystal X-ray diffraction. It was shown that this $\mathrm{Zn}(\mathrm{II})$ complex can catalyze the $\mathrm{A}^{3}$ coupling reaction of benzaldehyde, piperidine, and phenylacetylene with a moderate catalytic activity.

\section{Acknowledgement}

This project was supported by the National Natural Science Foundation of China (No. 21171132), the Natural Science Foundation of Shandong (ZR2014BL003), the project of Shandong Province Higher Educational Science and
Technology Program (J14LC01) and Science Foundation of Weifang.

\section{References}

[1] Borah, S.J., Das, D.K. (2016). Modified Monotmorillonite Clay Stabilized Silver Nanoparticles: An Active Heterogeneous Catalytic System for the Synthesis of Propargylamines. Catalysis Letters, 146: 656665.

[2] Peshkov, V.A., Pereshivko, O.P., EV, V.D.E. (2012). A Walk Around the $\mathrm{A}^{3}$-Coupling. Chemical Society Reviews, 41: 3790-3807.

[3] Layek, K., Chakravarti, R., Kantam, L.M., Maheswaran, H., Viru, A. (2011). Nanocrystalline Magnesium Oxide Stabilized Gold Nanoparticles: An Advanced Nanotechnology Based Recyclable Heterogeneous Catalyst Platform for the One-pot Synthesis of Propargylamines. Green Chemistry, 13: 2878-2887.

[4] Liu, L.L., Tai, X.S., Zhang, N.N., Meng, Q.G., Xin, C.L. (2016). Supported Au/MIL-53(Al): A Reusable Green Solid Catalyst for the Threecomponent Coupling Reaction of Aldehyde, Alkyne, and Amine. Reaction Kinetics, Mechanisms, and Catalysis, 119: 335-348.

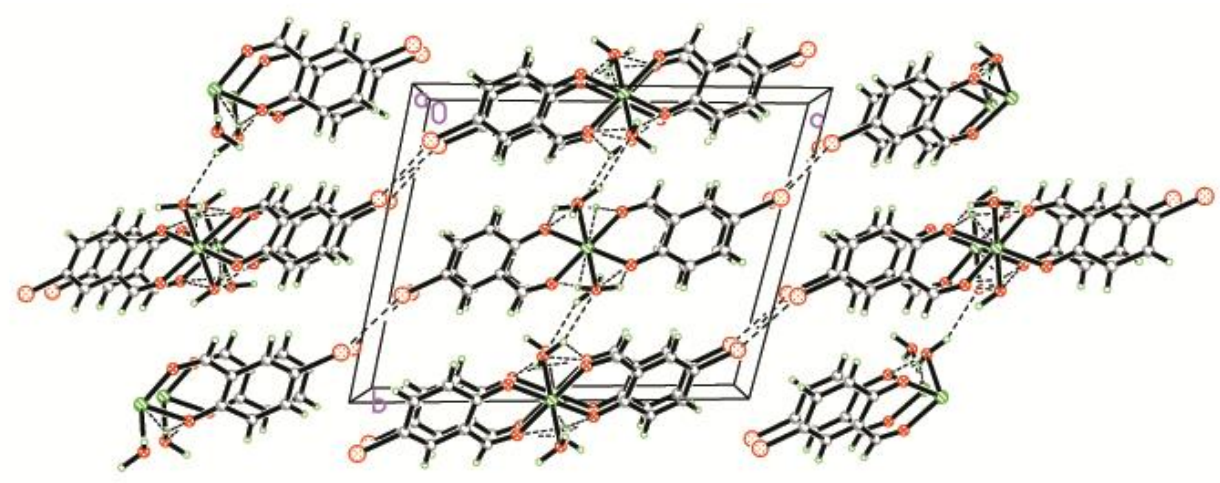

Figure 5. The perspective view of stacking of $\mathrm{Zn}(\mathrm{II})$ complex $\mathbf{C 1}$

Table 3. Coupling of benzaldehyde, piperidine, and phenylacetylene catalyzed by $\mathrm{Zn}(\mathrm{II}) \mathrm{complex}$ catalyst in dioxane[a]

\begin{tabular}{cccccc}
\hline Run & Catalyst & Solvent & Temperature $\left({ }^{\circ} \mathrm{C}\right)$ & Time $(\mathrm{h})$ & Conv. (\%) \\
\hline 1 & Zn(II) complex & 1,4-dioxane & 120 & 12 & 54.6 \\
2 & Zn(II) complex & 1,4-dioxane & 120 & 12 & 54.8 \\
3 & Zn(II) complex & 1,4-dioxane & 120 & 12 & 53.8 \\
4 & Zn(II) complex & 1,4-dioxane & 120 & 12 & 54.4 \\
\hline
\end{tabular}

[a] Reaction conditions: aldehyde $(0.125 \mathrm{mmol})$, amine $(0.17 \mathrm{mmol})$, alkyne $(0.15 \mathrm{mmol})$, catalyst $(70 \mathrm{mg})$, dioxane $(1.500 \mathrm{~g})$ 
[5] Liu, L.L., Tai, X.S., Yu, G.L., Guo, H.M., Meng, Q.G. (2016). Gold and Silver Nanoparticles Supported on Metal-organic Frameworks: a Highly Active Catalyst for Threecomponent Coupling Reaction. Chemical Research in Chinese Universities, 32: 443-450.

[6] Sharma, R., Sharma, S., Gaba, G. (2014). A Silica Nanospheres Supported Diazafluorene Iron Complex: An Efficient and Versatile Nanocatalyst for the Synthesis of Propargylamines from Terminal alkynes, Dihalomethane and Amines. RSC Advances, 4: 49198-49211.

[7] Murai, T., Mutoh, Y., Ohta, Y., Murakami. M. (2004). Synthesis of Tertiary Propargylamines by Sequential Reactions of in Situ Generated Thioiminium Salts with Organolithium and Magnesium Reagents. Journal of the American Chemical Society, 126: 5968-5969.

[8] Periasamy, M., Reddy, P.O., Edukondalu, A., Dalai, M., Alakonda, L.M., Udaykumar, B. (2014). Zinc Salt Promoted Diastereoselective Synthesis of Chiral Propargylamines Using Chiral Piperazines and their Enantioselective Conversion into Chiral Allenes. European Journal of Organic Chemistry, 2014: 60676076.

[9] Gholinejad, M., Saadati, F., Shaybanizadeh, S., Pullithadathil, B. (2016). Copper Nanoparticles Supported on Starch Micro Particles as a Degradable Heterogeneous Catalyst for Three-component Coupling Synthesis of Propargylamines. RSC Advances, 6: 49834991.

[10] Samai, S., Nandi, G.C., Singh, M. (2010). An Efficient and Facile One-pot Synthesis of Propargylamines by Three-component Coupling of Aldehydes, Amines, and Alkynes via $\mathrm{C}-\mathrm{H}$ Activation Catalyzed by $\mathrm{NiCl}_{2}$. Tetrahedron Letters, 51: 5555-5558.

[11] Fukuzumi, S., Kojim, T., Lee, Y.M., Nama, W. (2017). High-valent Metal-oxo Complexes Generated in Catalytic Oxidation Reactions Using Water As an Oxygen Source. Coordination Chemistry Reviews, 333: 44-56.

[12] Liu, L.L., Tai, X.S., Liu, M.F., Li, Y.F., Feng, Y.M., Sun, X.R. (2015). Supported Au/MOF-5: A Highly Active Catalyst for Threecomponent Coupling Reactions. CIESC Journal, 66(5): 1738-1747.

[13] Andrea, V., Salvatore, B., Cristina, T., Walter, B., Marino, B., Claudia, G. (2016). Dinuclear Di(N-heterocyclic carbene) Iridium(III) Complexes as Catalysts in Transfer Hydrogenation. European Journal of Inorganic Chemistry, 2016: 247-251.
[14] Miriam, N.G., Kohsuke, M., Ai, N., Yasutaka, K., Hiromi, Y. (2016). Highly Efficient Ru/carbon Catalysts Prepared by Pyrolysis of Supported Ru Complex Towards the Hydrogen Production from Ammonia Borane. Applied Catalysis A: General, 527: 45-52.

[15] Yang, D., Odoh, S.O., Borycz, J., Wang, T.C., Farha, O.K., Hupp, J.T., Cramer, C.J., Gagliardi, L., Gates, B.C. (2016). Tuning Zr6 Metal-Organic Framework (MOF) Nodes as Catalyst Supports: Site Densities and Electron-Donor Properties Influence Molecular Iridium Complexes as Ethylene Conversion Catalysts. ACS Catalysis, 6: 235-247.

[16] Thangavel, S., Boopathi, S., Mahadevaiah, N., Kolandaivel, P., Pansuriya, P.B., Friedrich, H.B. (2016). Catalytic Oxidation of Primary aromatic alcohols Using Half Sandwich Ir(III), Rh(III) and Ru(II) Complexes: A Practical and Theoretical Study. Journal of Molecular Catalysis A: Chemical, 423: 160-171.

[17] Tai, X.S., Liu, L.L., Yin, J. (2014). Synthesis, Crystal Structure of Tetra-Nuclear Macrocyclic $\mathrm{Cu}(\mathrm{II})$ Complex Material and Its Application as Catalysts for $\mathrm{A}^{3}$ Coupling Reaction. Journal of Inorganic and Organometallic Polymers and Materials, 24(6): 1014-1020.

[18] Tai, X.S., Liu, L.L. (2015). Synthesis, Crystal Structure of a Mg(II) Complex Materials and Its Application as Catalysts for $\mathrm{A}^{3}$ Coupling Reaction. The Open Materials Science Journal, 9: 1-5.

[19] Sheldrick, G.M. (1997). SHELXL-97, Program for Crystal Structure Solution. University of Göttingen: Göttingen, Germany.

[20] Sheldrick, G.M. (1997). SHELXTL-97, Program for Crystal Structure Refinement. University of Göttingen: Göttingen, Germany.

[21] Nakamoto, K. (1978). Infrared and Ramen Spectra of Inorganic and Coordination Compounds. $3^{\text {rd }}$ ed.; John Wiley and Sons: New York, NY, USA, Volume 1, pp. 359-368.

[22] Tai, X.S., Wang, X., You, H.Y. (2016). Synthesis, Crystal Structure and Antitumor Activity of a New $\mathrm{Zn}(\mathrm{II})$ Complex Based on N-Acetylphenylalanine and 1,10-Phenanthroline. Chinese Journal of Structural Chemistry, 35: 586-590. 